\title{
Burnout in Canadian urology: Cohort analysis from the 2018 Canadian Urological Association census
}

\author{
Ernest P. Chan, $M D^{\prime}$; Leandra S. Stringer, $M D^{\prime}$; Adam Forster, $M D^{\prime}$; William D. Meeks, $M D^{2}$; \\ Raymond Fang, MD2; Julie Franc-Guimond, MD'; Alp Sener, MD, PhD ${ }^{1,4}$
}

'Department of Surgery, Division of Urology, Schulich School of Medicine \& Dentistry, Western University, London, ON, Canada; 2Data Management and Statistical Analysis, American Urological Association, Linthicum, Maryland, United States; ${ }^{3}$ Department of Surgery, Division of Pediatric Urology, University of Montreal, QC, Canada; ${ }^{4}$ Department of Microbiology and Immunology, Schulich School of Medicine and Dentistry, Western University, London, ON, Canada

Cite as: Chan EP, Stringer LS, Forster A, et al. Burnout in Canadian urology: Cohort analysis from the 2018 Canadian Urological Association census. Can Urol Assoc J 2021;15(6Suppl1):S5-15. http://dx.doi.org/10.5489/cuaj.7232

\section{Appendix available at cuaj.ca}

\section{Abstract}

Introduction: Physician burnout is associated with medical error, patient dissatisfaction, and poorer physician health. Urologists have reported high levels of burnout and poor work-life integration compared with other physicians. Burnout rates among Canadian urologists has not been previously investigated. We aimed to establish the prevalence of Canadian urologist burnout and associated factors.

Methods: In the 2018 Canadian Urological Association census, the Maslach Burnout Inventory questions were assigned to all respondents. Responses from 105 practicing urologists were weighted by region and age group to represent 609 urologists in Canada. Burnout was defined as scoring high on the scales of emotional exhaustion or depersonalization. Demographic and practice variables were assessed to establish factors associated with burnout. Comparisons were made to the results of the 2016 American Urological Association census.

Results: Overall, $31.8 \%$ of respondents met the criteria for burnout. There was no effect of subspecialty practice or practice setting on burnout. On univariate analysis, rates of burnout were highest among urologists under financial strain $(50.8 \%)$, female urologists $(45.3 \%)$, and early-to-mid-career urologists (37.7-41.8\%). Factors associated with demanding practices and poor work-life integration were predictive of burnout. A total of $12.2 \%$ of urologists reported seeking burnout resources and $54.0 \%$ wished there were better resources available.

Conclusions: Urologist burnout in Canada is lower than reported in other countries, but contributing factors are similar. Urologists who report demanding clinical practices (particularly in early-tomid career), poor work-life integration, financial strain, and female gender may benefit from directed intervention for prevention and management of burnout. Burnout resources for Canadian urologists require further development.

\section{Introduction}

The term "burnout" was first described by Freudenberger in 1980 and was defined as "the extinction of motivation or incentive, especially where one's devotion to a cause or relationship fails to produce the desired results." 1 This concept was further developed by Maslach et $\mathrm{al}^{2}$ and has since been divided into three domains: emotional exhaustion (EE), depersonalization (DP)/cynicism, and low personal accomplishment (PA)/professional efficacy. These domains can each be assessed via the Maslach Burnout Inventory $(\mathrm{MBI})$, a validated tool used in medical disciplines ${ }^{3}$ and the corporate workspace ${ }^{4}$ to evaluate burnout.

Burnout among physicians has been shown to be associated with lower-quality care, increased medical errors, and lower patient satisfaction..$^{5-8}$ It is associated with reduced physician productivity, increased physician turnover, decreased patient access, and heightened costs..$^{9,10}$ The annual cost of physician burnout in Canada due to early physician retirement and reduced clinical hours is estimated to be $\$ 213$ million. ${ }^{11}$ Substance abuse, depression, suicidal ideation, poor self-care, and motor vehicle crashes are more prevalent among physicians experiencing burnout. ${ }^{12,13}$ Given the significant consequences of physician burnout, Shanafelt et al began surveying American physicians and workers in other fields starting in 2011 to chronicle the changing rates of burnout and satisfaction with work-life integration among physicians relative to the general population. ${ }^{14}$ In 2015, Shanafelt et al reported that burnout among urologists was $64 \%$, which was significantly increased from $41 \%$ in $2011 .{ }^{15}$ This report also indicated that urologists had the second worst work-life balance (behind neurosurgeons). Based on these findings, many urologists raised concerns regarding early retirement and potential substance abuse among practicing urologists ${ }^{1}$ and the negative impact on prospective applicants. ${ }^{16}$

To further investigate the prevalence of burnout among urologists in the United States, North et al administered the 
$\mathrm{MBI}$ to assess burnout among American urologists through the 2016 American Urological Association (AUA) census. ${ }^{17}$ The results of this investigation identified burnout in 38.8\% of practicing urologists, with $17.2 \%$ scoring high for $\mathrm{EE}$ and $37.1 \%$ for DP. ${ }^{17}$ Specific practice features associated with burnout included more patient visits per week, younger age, non-pediatric or oncologic subspeciality, and practice size greater than two urologists. ${ }^{17}$

The data presented herein is the first study to examine the prevalence in burnout among Canadian urologists through the 2018 Canadian Urological Association (CUA) census. Through our analysis, we aim to identify trends, patterns, and predisposing factors for burnout among Canadian urologists.

\section{Methods}

\section{Sample population}

The CUA conducted a census survey from August 8 to October 10, 2018 that was completed online and received through electronic communications. Maslach Burnout Inventory questions were included for all respondents. The 105 practicing urologists who completed the CUA census were included in this study and weighted by region and age groups to represent 609 urologists in Canada. A total of 702 members received an email invitation to participate in the CUA census, which included practicing urologists, urology residents and fellows, non-urologist physicians, non-physician healthcare professionals, and researchers. Non-clinical members of the CUA were excluded from analysis in this study $(n=93)$.

\section{Burnout}

Burnout among urologists was measured using the $\mathrm{MBI}$ questionnaire, which consisted of 22 validated questions. The $\mathrm{MBI}$ questions were organized into the three burnout domains of EE, DP, and PA. This survey was designed in similar fashion to the 2016 AUA census to allow for comparison between results. ${ }^{17}$ Consistency with the AUA census results and other studies was maintained through defining burnout as scoring high in the EE (score 27 or greater) or DP (score 10 or greater) categories. ${ }^{17-20}$

\section{Study measures}

Data collected from the 2018 CUA census also included information on participant demographics, education and training, practice characteristics, burnout resource use, and personal factors. The CUA census questions pertaining to this study are included in the Appendix (available at cuaj.ca).

\section{Statistical analysis}

Univariate inferential analyses were used to identify the association between urologist burnout and various demographic and professional characteristics. Participant responses were also evaluated in terms of the burnout domains: EE (high vs. low/moderate), DP (high vs. low/ moderate), and PA (low vs. high/moderate). Statistical calculations were used to evaluate possible age group and gender effects on urologist burnout among different domains. For age group differences, respondents were divided into two groups based on the median age of respondents who met criteria for burnout, which was calculated at 46 years. Respondents aged up to 46 years were compared to respondents 47 years and greater. Where applicable, comparisons between the 2018 CUA and 2016 AUA census were performed to identify differences between the two census results. P-values were not generated for comparison between these groups due to the greater number of AUA respondents.

Pearson's Chi-squared test of independence was used in univariate analyses to identify whether burnout was associated with each of the demographic and professional characteristics individually and when adjusting for other characteristics in the study. This was also performed in our subgroup analyses. All tests were two-sided, with a type I error level of 0.05. All analyses were performed using standard statistical software IBM-SPSS ${ }^{\circledR}$ version 22.

\section{Results}

\section{Sample population}

A total of 105 practicing urologists completed the survey in full and were statistically weighted by region and age group to represent 609 urologists in Canada. The overall response rate of the survey was $19.5 \%$ (137/702) and the response rate for practicing urologists was $17.2 \%$ (105/609). Demographic and practice data are included in Table 1. General urology comprised $30.2 \%$ of respondents, followed by oncology $(17.4 \%)$, endourology/stone disease $(14.9 \%)$, and pediatrics $(11.8 \%)$. Most respondents participated on call once a week (34.4\%) or 2-3 days per week $(29.9 \%)$.

Overall, $31.8 \%$ of respondents met the definition for burnout. Of the $\mathrm{MBI}$ domains, $8.0 \%$ reported high levels of $E E, 31.8 \%$ reported high levels of DP, and $10.6 \%$ of respondents indicated low sense of PA (Table 2). Table 3 outlines factors evaluated in our univariate analysis. 


\begin{tabular}{|c|c|c|}
\hline Category & $\mathbf{n}$ & $\begin{array}{l}\text { Percent } \pm \\
\text { MOE (\%) }\end{array}$ \\
\hline \multicolumn{3}{|l|}{ Demographic factors } \\
\hline \multicolumn{3}{|l|}{ Gender } \\
\hline Female & 53 & $8.6 \pm 4.1$ \\
\hline Male & 556 & $91.4 \pm 4.1$ \\
\hline \multicolumn{3}{|l|}{ Current marital status } \\
\hline Single & 13 & $2.2 \pm 2.6$ \\
\hline Single in a committed relationship & 47 & $7.8 \pm 2.8$ \\
\hline Married & 515 & $85.9 \pm 5.3$ \\
\hline Divorced & 18 & $3.0 \pm 3.5$ \\
\hline Divorced and in a committed relationship & 7 & $1.1 \pm 1.8$ \\
\hline \multicolumn{3}{|l|}{ How many children do you have? } \\
\hline 0/None & 109 & $17.8 \pm 4.6$ \\
\hline $1-2$ & 176 & $28.9 \pm 7.9$ \\
\hline $3-4$ & 195 & $32.1 \pm 8.7$ \\
\hline 5 or more & 129 & $21.2 \pm 7.1$ \\
\hline \multicolumn{3}{|l|}{ What is your religious/faith background? } \\
\hline Christianity & 337 & $55.3 \pm 7.7$ \\
\hline Judaism & 106 & $17.4 \pm 5.6$ \\
\hline Islam & 17 & $2.8 \pm 2.8$ \\
\hline Buddhism & 4 & $0.7 \pm 1.2$ \\
\hline Hinduism & 12 & $2.0 \pm 2.0$ \\
\hline Other & 133 & $21.9 \pm 5.9$ \\
\hline \multicolumn{3}{|l|}{ Practice characteristics } \\
\hline \multicolumn{3}{|l|}{ Primary subspecialty } \\
\hline General without subspecialty & 184 & $30.2 \pm 6.3$ \\
\hline Oncology & 107 & $17.5 \pm 4.8$ \\
\hline Pediatrics & 72 & $11.8 \pm 4.4$ \\
\hline Endourology/stone disease & 91 & $14.9 \pm 5.8$ \\
\hline FPMRS & 35 & $5.8 \pm 3.9$ \\
\hline Erectile dysfunction & 18 & $2.9 \pm 3.0$ \\
\hline Male infertility & 14 & $2.2 \pm 2.8$ \\
\hline Renal transplantation & 12 & $2.0 \pm 2.6$ \\
\hline Male genitourinary reconstruction & 21 & $3.4 \pm 3.9$ \\
\hline Robotic surgery & 19 & $3.1 \pm 3.8$ \\
\hline Laparoscopic surgery & 37 & $6.0 \pm 4.4$ \\
\hline \multicolumn{3}{|l|}{ How often are you on call? } \\
\hline Everyday & 39 & $6.4 \pm 3.5$ \\
\hline Every other day & 46 & $7.5 \pm 4.6$ \\
\hline 2-3 days per week & 182 & $29.9 \pm 6.9$ \\
\hline Once a week & 210 & $34.4 \pm 8.4$ \\
\hline 2-3 days per month & 51 & $8.4 \pm 5.6$ \\
\hline Once a month & 8 & $1.4 \pm 1.5$ \\
\hline Less than once a month & 66 & $10.9 \pm 4.6$ \\
\hline Never on call & 7 & $1.2 \pm 1.0$ \\
\hline
\end{tabular}

Table 1 (cont'd). Weighted demographic variables, practice characteristics, personal factors, and burnout resource use of participants who completed the 2018 CUA census

\begin{tabular}{lr}
\hline Category & Percent \pm \\
& MOE (\%)
\end{tabular}

\section{Personal factors}

How many times do you exercise on a weekly basis

$\begin{array}{lll}0 / \text { None } & 109 & 17.8 \pm 4.6 \\ 1-2 & 176 & 28.9 \pm 7.9 \\ 3-4 & 195 & 32.1 \pm 8.7 \\ 5+ & 129 & 21.2 \pm 7.1\end{array}$

Do you wish you had more time for hobbies outside of work?

Yes

No

Would you describe your social life as active?

Yes

No

How would you rate your personal physical health?

Excellent
Good
Fair
Poor

Poor

Do you have any outstanding malpractice claims/lawsuits

Yes

No

Are you under financial strain?

$$
\text { Yes }
$$

$117 \quad 19.3 \pm 6.3$

No

\section{Burnout resource use}

Are there resources available to manage stress and burnout within your organization?

$\begin{array}{lll}\text { Yes } & 240 & 39.5 \pm 8.6 \\ \text { No } & 132 & 21.7 \pm 6.7 \\ \text { I don't know } & 236 & 38.8 \pm 6.9\end{array}$

Are the resources available within your organization to manage stress and burnout adequate?

$\begin{array}{lcc}\text { Yes } & 89 & 14.7 \pm 6.4 \\ \text { No } & 131 & 21.6 \pm 6.3 \\ \text { I don't know } & 388 & 63.8 \pm 8.4\end{array}$

Have you used available resources to manage stress and burnout?

$\begin{array}{lcc}\text { Yes } & 71 & 12.2 \pm 6.6 \\ \text { No } & 514 & 87.8 \pm 6.6\end{array}$

Do you wish there were more/better resources available to manage burnout within your organization?

$\begin{array}{lll}\text { Yes } & 329 & 54.0 \pm 8.7 \\ \text { No } & 280 & 46.0 \pm 8.7\end{array}$

CUA: Canadian Urological Association; FPMRS: female pelvic medicine and reconstructive surgery; MOE: margin of error. 


\section{Practice factors}

There was no effect of subspecialty practice $(p=0.979)$, fellowship training $(p=0.07)$, or primary practice setting $(p=0.432)$ on burnout (Table 3$)$. Urologists employed by others had higher rates of burnout than those who were partners in a private practice or in solo private practice $(p=0.009)$. Respondents who used electronic health records (EHR) exclusively reported higher rates of burnout $(\mathrm{p}=0.014)$. Being on call more than once a week was associated with higher rates of burnout $(p=0.002)$. Urologists with a more demanding clinical practice reported higher rates of burnout, which was determined by: spending more than 15 minutes with a patient in a typical office visit $(p=0.006)$, working 61 or more clinical hours per week ( $p=0.003$ ), seeing 75 or less patient encounters per week $(p=0.019)$, and participating in a telemedicine program $(p=0.003)$ (Table 3$)$.

\section{Personal factors}

Female gender was associated with higher rates of burnout ( $p=0.028$ ) (Table 1). Almost all respondents $(91.2 \%)$ indicated that they wished they had more time for hobbies outside of work (Table 1). Most reported that they had an active social life (55.8\%) and excellent or good personal physical health $(32.4 \%$ and $52.7 \%$, respectively). A significant portion reported that they were under financial strain $(19.3 \%)$ or had any outstanding malpractice claims/ lawsuits (13.9\%) (Table 1). Use of illicit substances and alcohol were reported at $2.1 \%$ and $82.4 \%$, respectively.

Financial strain was associated with the highest rates of burnout $(50.8 \% ; \mathrm{p}<0.001)$. Outstanding malpractice claims/lawsuits was inversely associated with burnout $(p=0.002)$. Respondents who indicated that they wished for more time for hobbies had higher burnout rates $(p<0.001)$.
Burnout was not associated with personal physical health $(p=0.191)$, active social life $(p=0.562)$, or alcohol use $(p=0.804)$.

Burnout resources were available to $39.5 \%$ of respondents; $12.2 \%$ of respondents had used these resources but $21.6 \%$ indicated that resources within their organization were not adequate (Table 1). More than half (54.0\%) wished there were more or better resources available to manage burnout within their organization. Urologists who used burnout resources $(p=0.001)$ or wished there were more/better burnout resources $(p=0.013)$ had higher burnout rates (Table 3 ).

\section{MBI domains}

We examined the prevalence of three burnout domains identified by the MBI: EE, DP, and low PA. Top factors associated with each $\mathrm{MBI}$ domain are listed in Table 4. Common factors associated with both high levels of DP and low PA were female gender $(p=0.028$ and $p<0.001$, respectively) and financial strain $(p<0.001$ and $p<0.001)$. Non-Jewish/Christian faith was associated with high levels of $E E(p<0.001)$ and high levels of DP $(p<0.001)$.

\section{Comparisons of age groups}

Respondents were divided into two groups based on the median age of respondents who met criteria for burnout (calculated at 46 years). Burnout was greater in the $<46$ years old group ( $42.6 \%$ vs $25.3 \%, \mathrm{p}<0.001)$, as were levels of high $\mathrm{EE}(\mathrm{p}=0.024)$ and DP $(\mathrm{p}<0.001)$ (Table 2). Factors associated with burnout are significantly different between respondents who are 46 years of age and younger and respondents who are 47 years of age and older, as outlined in Table 5.

Table 2. Respondent burnout based on Maslach Burnout Inventory with scoring on different burnout domains and subgroups generated from responses to the 2018 CUA census

\begin{tabular}{|c|c|c|c|c|c|c|c|c|c|c|c|c|}
\hline \multirow[b]{2}{*}{ Group } & \multicolumn{3}{|c|}{ Burnout } & \multicolumn{3}{|c|}{ Emotional exhaustion } & \multicolumn{3}{|c|}{ Depersonalization } & \multicolumn{3}{|c|}{ Personal accomplishment } \\
\hline & Yes & $\mathrm{Cl}$ & p & High & $\mathrm{Cl}$ & p & High & $\mathrm{Cl}$ & p & Low & $\mathbf{C l}$ & p \\
\hline \multicolumn{13}{|l|}{ CUA vs. AUA } \\
\hline CUA (\%) & 31.8 & $(24.1,39.5)$ & * & 8.0 & $(3.2,12.8)$ & * & 31.8 & $(24.1,39.5)$ & * & 10.6 & $(6.7,14.5)$ & * \\
\hline AUA (\%) & 36.2 & $(33.5,38.9)$ & & 16.5 & $(14.5,18.5)$ & & 34.6 & $(32.0,37.2)$ & & 8.2 & $(7.1,10.1)$ & \\
\hline \multicolumn{13}{|l|}{ Age groups } \\
\hline$<46$ years old $(\%)$ & 42.6 & $(36.5,48.7)$ & $<0.001$ & 11.2 & $(7.4,15.0)$ & 0.024 & 42.6 & $(36.5,48.7)$ & $<0.001$ & 11.5 & $(9.1,14.0)$ & 0.538 \\
\hline$>47$ years old $(\%)$ & 25.3 & $(19.8,30.8)$ & & 6.0 & $(3.0,9.0)$ & & 25.3 & $(19.8,30.8)$ & & 10.0 & $(7.0,13.0)$ & \\
\hline \multicolumn{13}{|l|}{ Gender } \\
\hline Female (\%) & 45.3 & $(22.7,38.5)$ & 0.028 & 0.0 & - & - & 45.3 & $(22.7,38.5)$ & 0.028 & 49.1 & $(45.7,52.5)$ & $<0.001$ \\
\hline Male (\%) & 30.6 & $(37.2,53.4)$ & & 8.7 & $(3.9,13.5)$ & & 30.6 & $(37.2,53.4)$ & & 6.9 & $(3.8,10.0)$ & \\
\hline
\end{tabular}

Burnout was defined as scoring high on emotional exhaustion or depersonalization. Comparisons subgroups included CUA vs. AUA, age groups, and gender. ${ }^{*}$ Unable to compute p due to power differences between AUA and CUA surveys. AUA: American Urological Association; Cl: 90\% confidence interval; CUA: Canadian Urological Association. 
Table 3. Univariate analysis of variables associated with burnout among respondents to the 2018 CUA census

\begin{tabular}{|c|c|c|c|}
\hline Category & $\mathbf{n}$ & Percent & $\mathbf{p}$ \\
\hline Personal factors & & & 0.001 \\
\hline Age grouped & 55 & $37.7 \%$ & \\
\hline 40 years old or under & 59 & $41.8 \%$ & \\
\hline $41-48$ years old & 43 & $26.7 \%$ & \\
\hline $49-59$ years old & 37 & $23.0 \%$ & \\
\hline \multicolumn{4}{|l|}{ Over 60 years old } \\
\hline Gender & & & 0.028 \\
\hline Male & 170 & $30.6 \%$ & \\
\hline Female & 24 & $45.3 \%$ & \\
\hline Marital status & & & $0.047 *$ \\
\hline Other & 18 & $21.4 \%$ & \\
\hline Married & 166 & $32.2 \%$ & \\
\hline $\begin{array}{l}\text { What is your religious/faith } \\
\text { background? }\end{array}$ & & & $<0.001$ \\
\hline Judaism & 36 & $34.0 \%$ & \\
\hline Christianity & 83 & $24.7 \%$ & \\
\hline Other & 74 & $44.6 \%$ & \\
\hline How many children do you have? & & & $<0.001 *$ \\
\hline 0/None & 7 & $9.7 \%$ & \\
\hline $1-2$ & 44 & $43.5 \%$ & \\
\hline $3-4$ & 45 & $21.1 \%$ & \\
\hline \multicolumn{4}{|l|}{ Practice factors } \\
\hline $\begin{array}{l}\text { Please select the primary subspecialty } \\
\text { area in which you practice. }\end{array}$ & & & 0.979 \\
\hline General without subspecialty & 59 & $32.1 \%$ & \\
\hline Subspecialty & 135 & $31.8 \%$ & \\
\hline $\begin{array}{l}\text { Please select your primary practice } \\
\text { setting }\end{array}$ & & & 0.432 \\
\hline $\begin{array}{l}\text { Academic medical center/medical } \\
\text { school }\end{array}$ & 92 & $30.4 \%$ & \\
\hline Other & 102 & $33.3 \%$ & \\
\hline Fellowship status & & & 0.070 \\
\hline No fellowship & 53 & $26.9 \%$ & \\
\hline Fellowship & 141 & $34.2 \%$ & \\
\hline Employment status & & & 0.009 \\
\hline I am employed by others & 73 & $39.2 \%$ & \\
\hline I am a partner or in solo practice & 121 & $28.6 \%$ & \\
\hline No. of urologists in your practice & & & 0.075 \\
\hline 3 or less & 79 & $28.2 \%$ & \\
\hline 4 or more & 115 & $35.0 \%$ & \\
\hline
\end{tabular}

Table 3 (cont'd). Univariate analysis of variables associated with burnout among respondents to the 2018 CUA census

\begin{tabular}{lccc}
\hline Category & $\mathbf{n}$ & Percent & $\mathbf{p}$ \\
\hline Practice factors (cont'd) & & & \\
\hline $\begin{array}{l}\text { Do you use an electronic health } \\
\text { record (EHR) system to record patient }\end{array}$ & & & $\mathbf{0 . 0 1 4}$ \\
$\begin{array}{l}\text { information? } \\
\quad \text { I use EHR only }\end{array}$ & 131 & $35.6 \%$ & \\
$\quad$ I use both EHR and paper records/l & 63 & $26.1 \%$ & \\
$\quad$ use paper records only & & & \\
Number of vacation weeks & & & 0.813 \\
$\quad$ 5 or less & 88 & $32.4 \%$ & \\
$\quad$ or more & 106 & $31.5 \%$ & \\
How often are you on call? & & & $\mathbf{0 . 0 0 2}$ \\
$\quad$ More than once a week & 102 & $38.3 \%$ & \\
$\quad$ Once a week or less & 92 & $26.8 \%$ & \\
\hline
\end{tabular}

\section{Clinical practice}

Number of minutes spent with a patient in a typical office visit

$$
\text { Less than } 15 \mathrm{~min}
$$

Greater than $15 \mathrm{~min}$

Number of hours spent on clinical activities in a week

$$
\begin{array}{lcc}
60 \text { or less } & 110 & 27.7 \% \\
61 \text { or more } & 84 & 39.6 \%
\end{array}
$$

Number of patient visit/encounters per week

$$
75 \text { or less }
$$$$
76 \text { or more }
$$

Percent of patient visits/encounters by female patients

$\begin{array}{lll}29 \% \text { or less } & 95 & 44.6 \% \\ 30 \% \text { or more } & 99 & 25.0 \%\end{array}$

Number of hours spent on non-clinical activities* in a week

$\begin{array}{lcc}9 \text { or less } & 63 & 28.4 \% \\ 10 \text { or more } & 131 & 33.9 \%\end{array}$
Have you participated in any quality months?

$\begin{array}{lll}\text { Yes } & 99 & 28.7 \% \\ \text { No/l don't know } & 95 & 36.0 \%\end{array}$

Do you participate in a telemedicine program?

$\begin{array}{lcc}\text { No } & 138 & 28.9 \% \\ \text { Yes, in less than } 10 \% \text { of my patients } & 56 & 42.4 \%\end{array}$

Burnout factors

Are the resources available within your organization to manage stress and burnout adequate?

$\begin{array}{lcc}\text { Yes } & 77 & 32.0 \% \\ \text { No/l don't know } & 117 & 31.8 \%\end{array}$

*Non-clinical activities (e.g., administration, teaching, research, etc.). CUA: Canadian Urological Association.
0.056

0.003

0.006

0.003

0.019

$<0.001$

0.163

0.968 


\begin{tabular}{|c|c|c|c|}
\hline \multicolumn{4}{|c|}{$\begin{array}{l}\text { Table } 3 \text { (cont'd). Univariate analysis of variables } \\
\text { associated with burnout among respondents to the } 2018 \\
\text { CUA census }\end{array}$} \\
\hline Category & $\mathbf{n}$ & Percent & $\mathbf{p}$ \\
\hline \multicolumn{4}{|l|}{ Burnout factors (cont'd) } \\
\hline $\begin{array}{l}\text { Have you used available resources to } \\
\text { manage stress and burnout? }\end{array}$ & & & 0.001 \\
\hline Yes & 34 & $47.9 \%$ & \\
\hline No & 149 & $29.0 \%$ & \\
\hline $\begin{array}{l}\text { Do you wish that there were more/ } \\
\text { better resources available to manage } \\
\text { burnout within your organization? }\end{array}$ & & & 0.013 \\
\hline Yes & 119 & $36.2 \%$ & \\
\hline No/l don't know & 75 & $26.8 \%$ & \\
\hline $\begin{array}{l}\text { How would you rate your personal } \\
\text { physical health? }\end{array}$ & & & 0.191 \\
\hline Excellent/good & 160 & $30.8 \%$ & \\
\hline Fair/poor & 34 & $37.8 \%$ & \\
\hline $\begin{array}{l}\text { Do you wish you had more time for } \\
\text { hobbies outside of work? }\end{array}$ & & & $<0.001 *$ \\
\hline Yes & 190 & $34.2 \%$ & \\
\hline No & 4 & $7.5 \%$ & \\
\hline $\begin{array}{l}\text { Would you describe your social life as } \\
\text { active? }\end{array}$ & & & 0.562 \\
\hline Yes & 105 & $30.9 \%$ & \\
\hline No & 89 & $33.1 \%$ & \\
\hline Are you under financial strain? & & & $<0.001$ \\
\hline Yes & 60 & $50.8 \%$ & \\
\hline No & 134 & $27.3 \%$ & \\
\hline $\begin{array}{l}\text { Do you have any outstanding } \\
\text { malpractice claims/lawsuits? }\end{array}$ & & & 0.002 \\
\hline Yes & 15 & $17.6 \%$ & \\
\hline No & 179 & $34.2 \%$ & \\
\hline Do you drink alcohol? & & & 0.804 \\
\hline Yes & 161 & $32.1 \%$ & \\
\hline No & 33 & $30.8 \%$ & \\
\hline No & 137 & $30.4 \%$ & \\
\hline
\end{tabular}

\section{Gender comparisons}

Burnout rates reported by female urologists were significantly higher than male respondents $(p=0.028)$ (Table 2$)$. Female urologists also reported higher levels of $\mathrm{DP}(\mathrm{p}=0.028)$ and low PA $(p<0.001)$ compared to their male colleagues (Table 2). None of the female urologists who completed the survey indicated high levels of EE.

All female census respondents who met criteria for burnout were subspecialized in pediatric urology $(n=24)$. Female urologists who did not meet the criteria for burnout included general urologists $(n=9)$, female pelvic medicine and reconstructive surgery urologists $(n=9)$, pediatric urologists $(n=8)$, and endourologists $(n=3)$. Factors associated with burnout in female and male respondents are outlined in Table 5.

\section{Comparison to 2016 AUA census}

Rates of burnout, EE, and DP were lower among 2018 CUA census respondents compared with 2016 AUA census respondents (Table 2). Factors more often associated with burnout in CUA respondents include female gender $(p<0.001)$ and $>60$ hours worked per week $(p=0.031)$ (Table 5). Factors associated with a lower prevalence of burnout among CUA respondents compared to AUA respondents included subspecialty practice $(p<0.001)$, $>100$ patient encounters per week $(\mathrm{p}<0.001)$, male gender $(p<0.001),>75$ patient encounters per week, and $\leq 60$ total hours worked per week $(p=0.031)$. In terms of age groups, respondents aged $45-54$ years in the 2016 AUA census were most likely to have burnout (43.4\%) compared to the 55-65 years group (17.4\%) in the 2018 CUA census $(p<0.001)$.

\section{Discussion}

Burnout in urology received considerable attention following the 2015 report by Shanafelt et al ${ }^{15}$ which indicated a $64 \%$ burnout rate among urologists. This finding, however, was based on 119 respondents, representing $1.7 \%$ of those invited to complete the survey, with questionable generalizability due to small sample size and possible response bias, as the primary survey focus was on burnout. To further evaluate the prevalence of urologist burnout and associated factors, North et al randomly assigned half of the respondents of the 2016 AUA census ( $n=1126)$ to complete the $\mathrm{MBI} .{ }^{17}$ Using matrix sampling to represent the entire cohort of 2301 who completed the census, $38.8 \%$ of urologists met the criteria for burnout. A lower burnout prevalence $(31.8 \%)$ is reported in this study among Canadian urologists, which is driven by high levels of DP and associated primarily with demanding clinical practices, early-to-mid career practice, poor work-life integration, financial strain, and female gender.

\section{Burnout domains}

Emotional exhaustion (EE) refers to feelings of being emotionally overextended and exhausted by one's work. ${ }^{2}$ Canadian urologists reported lower rates of EE $(8.0 \%$ vs. $17.2 \%$ ) compared to the 2016 AUA census data. EE among Canadian urologists was associated with working 50 or 


\begin{tabular}{|c|c|c|}
\hline Category & Percent & $\mathbf{p}$ \\
\hline \multicolumn{3}{|l|}{ Emotional exhaustion } \\
\hline $41-48$ years old & 21.8 & 0.001 \\
\hline Fair/poor physical health & 18.7 & 0.001 \\
\hline Non-Jewish/Christian faith & 17.4 & $<0.001$ \\
\hline$\geq 50$ clinical hours/week & 16.3 & 0.001 \\
\hline Not socially active & 14.8 & $<0.001$ \\
\hline \multicolumn{3}{|l|}{ Depersonalization } \\
\hline Financial strain & 50.9 & $<0.001$ \\
\hline $\begin{array}{l}\text { Use of stress/burnout } \\
\text { resources }\end{array}$ & 48.2 & 0.001 \\
\hline Female gender & 44.8 & 0.028 \\
\hline Non-Jewish/Christian faith & 44.6 & $<0.001$ \\
\hline$\leq 29 \%$ visits by female patients & 44.5 & $<0.001$ \\
\hline \multicolumn{3}{|l|}{ Low personal accomplishment } \\
\hline Female gender & 49.1 & $<0.001$ \\
\hline Telemedicine use & 28.9 & $<0.001$ \\
\hline Financial strain & 20.8 & $<0.001$ \\
\hline$>15 \mathrm{~min} /$ patient & 19.2 & $<0.001$ \\
\hline$\leq 75$ patients/week & 18.7 & $<0.001$ \\
\hline
\end{tabular}

more clinical hours per week. This is consistent with North et al, who reported that American urologists with more demanding clinical practices were more likely to report burnout. ${ }^{17}$ Perceived job demands and emotional labor has also been associated with EE in medical residents and specialists. ${ }^{21}$ Additionally, EE was associated with personal factors, including younger age (41-48 years old), fair/poor physical health status, religious affiliation, and lack of social activity. Interventions to improve physical health and social activity may reduce burnout in urologists affected primarily by EE.

Depersonalization (DP) measures an unfeeling and impersonal response towards recipient's of one's service, care, treatment, or instruction. ${ }^{2}$ Maslach had previously described DP among professionals as a coping mechanism for stress. ${ }^{22,23}$ This is consistent with findings that DP among internal medicine specialists and residents was greater in those who reported higher emotional labor and more hours worked per week. ${ }^{21}$ DP as distancing against emotional labor may be harmful to relationships with colleagues and patients. ${ }^{24}$ Canadian urologists reported lower rates of DP (31.8\% vs. $37.1 \%$ ) compared to the respondents from the 2016 AUA census. ${ }^{17}$ High levels of DP among CUA respondents was associated with greater likelihood of seeking burnout resources and support, which is compatible with DP (or cynicism) as a form of adaptive response to burnout.
Table 5. Most prevalent factors associated with burnout among respondents to the 2018 CUA census based on subgroup analyses, including age groups ( $<46$ years vs. $\geq 47$ years old), gender (male vs. female), and comparison with 2016 AUA census

\begin{tabular}{|c|c|c|}
\hline Category & Percent (\%) & $\mathbf{p}$ \\
\hline \multicolumn{3}{|l|}{ Age groups } \\
\hline \multicolumn{3}{|l|}{$<46$ years old } \\
\hline Having 0 children & 100 & $<0.001$ \\
\hline Non-academic training center & 70.6 & $<0.001$ \\
\hline Being partner in a practice & 67.1 & $<0.001$ \\
\hline Working $\leq 9$ non-clinical hours & 69.8 & $<0.001$ \\
\hline$\leq 3$ or less urologists in practice & 60.8 & 0.025 \\
\hline \multicolumn{3}{|l|}{$\geq 47$ years old } \\
\hline Academic center & 70.7 & $<0.001$ \\
\hline$>15 \mathrm{~min} /$ patient & 64.9 & 0.004 \\
\hline$\leq 75$ patients/week & 72.1 & $<0.001$ \\
\hline Telemedicine use & 66.1 & 0.002 \\
\hline Christian faith & 60.2 & 0.007 \\
\hline \multicolumn{3}{|l|}{ Gender } \\
\hline \multicolumn{3}{|l|}{ Female } \\
\hline Greater than $15 \mathrm{~min} /$ patient & 30.4 & $<0.001$ \\
\hline$<30$ patients/clinic & 17.9 & 0.021 \\
\hline Financial strain & 28.2 & 0.001 \\
\hline \multicolumn{3}{|l|}{ Male } \\
\hline Married & 89.8 & 0.001 \\
\hline Non-Christian religion & 93.7 & 0.003 \\
\hline \multicolumn{3}{|l|}{ Comparison with AUA } \\
\hline \multicolumn{3}{|l|}{ Higher percentage burnout } \\
\hline Female gender & 34.3 & $<0.001$ \\
\hline$>60$ hours/week & 39.6 & 0.031 \\
\hline \multicolumn{3}{|l|}{ Lower percentage burnout } \\
\hline Subspecialty practice & 31.8 & $<0.001$ \\
\hline Male gender & 30.6 & $<0.001$ \\
\hline$>75$ encounters/week & 29.0 & $<0.001$ \\
\hline$\leq 60$ total hours/week & 27.7 & 0.031 \\
\hline
\end{tabular}

Low personal accomplishment (PA) is described as decreased feelings of competence and successful achievement in one's work, ${ }^{2}$ and was $10.6 \%$ among respondents to the 2018 CUA census. Respondents reporting female gender and financial strain were associated with both DP and low sense of PA. These factors together may represent a higher risk group requiring additional burnout prevention and organizational support.

\section{Demanding clinical practice}

Having a more demanding clinical practice is associated with burnout among urologists ${ }^{17,25,26}$ and other surgical specialties. ${ }^{27}$ In this study, respondents who spent more 
time with patients ( $>15$ minutes per patient), spent more hours on clinical activity ( $\geq 61$ hours per week), or participated in telemedicine programs had higher rates of burnout. Counterintuitively, seeing 75 or fewer patients per week was also associated with higher rates of burnout, which may be explained by management of more complex patients that require more time for counselling and treatment, or lack of available resources to see patients in an appropriate timeframe leading to long wait times.

Practice factors indicative of reduced autonomy, including being employed by others (vs. solo practice or partnership) and call frequency (more than once a week), were associated with higher rates of burnout among CUA census respondents. Lack of autonomy is a known causative factor for burnout, and may manifest through restrictive hospital bylaws, lack of personal freedom due to clinical responsibilities, or participation in a group practice. ${ }^{27,28}$ Exclusive use of EHR systems for clinical work was also associated with burnout, an effect that has been well-described and believed to be related to the increased time and effort spent on data entry, interference with work-life balance, and loss of control of workload. ${ }^{29-31}$

Subspecialty practice and practice setting (academic vs. other) were not associated with burnout in this study. This is in contrast with findings from the 2016 AUA census, which identified that general urologists were at higher risk of burnout, and that subspecialty practice in urologic oncology and pediatrics were protective against burnout. ${ }^{17}$ Prior AUA studies have similarly identified that academic practice and fellowship training are associated with increased job satisfaction. ${ }^{32}$ The difference between the CUA and AUA census findings may be related to inherent practice differences between urologists working in Canada and the United States. General urologists in the United States may have a more office-based practice with higher patient volume and lower acuity. This leads to time-consuming case loads and high overhead costs in a fee-for-service model when compared to academic subspecialists who are predominantly salary-based. Furthermore, Canadian urologists may experience less disparity in clinical hours, financial compensation, and patient volumes across specialties and practice settings in contrast to American urologists.

\section{Work-life integration}

The findings of this study are consistent with reports by Shanafelt et al that urologists have poor satisfaction with work-life integration. ${ }^{3,15}$ Almost all 2018 CUA census respondents indicated that they wished they had more time for hobbies. Fortunately, social and physical health are maintained among Canadian urologists and are noted protective factors against burnout. ${ }^{33}$ The current study also identifies that there is need for improvement in the availability and quality of burnout resources within organizations, as more than half of respondents expressed a desire for more or better resources and respondents that met the criteria for burnout reported higher rates of seeking burnout resources.

While a minority of respondents reported financial strain $(19.3 \%)$, those that did had the highest rates of burnout $(50.8 \%)$ across any individual variable. Financial strain has consistently been demonstrated as a risk factor for burnout, ${ }^{1,32,33}$ and in this study correlated with high levels of DP and low sense of PA. Additional organizational training and resources for financial planning, particularly for earlycareer urologists, may help to reduce the risk of developing financial strain.

\section{Burnout among early-to-mid-career urologists}

Previous studies have identified that urologists who were younger (less than 45 years) ${ }^{26,34}$ or mid-career ${ }^{17,33}$ (in practice for 11-25 years) experience higher rates of burnout. Our data is consistent with these findings; respondents in early-to-mid career (less than 46 years old) reported higher rates of burnout than their older colleagues (Table 2). Burnout in early-career urologists, especially those practicing at academic institutions, has been attributed to appointment to multiple administrative roles, ${ }^{1,26}$ perceived lack of autonomy, and frustration at work. ${ }^{35}$

In this study, early-to-mid-career urologists working in non-academic centers or with fewer urologists reported higher rates of burnout. This is consistent with findings of higher burnout among young private urologists in Ireland and the United Kingdom. ${ }^{26}$ Early-to-mid-career community urologists may lack institutional resources afforded by their academic counterparts and take more calls divided among a smaller group of urologists. Furthermore, midcareer physicians are known to work longer hours and take more calls compared to their older counterparts and have the highest rates of emotional exhaustion and burnout. This results in increased contemplation about pursuing a career outside of clinical medicine or leaving medicine altogether. ${ }^{36}$ Community practice may also contribute to burnout due to a perceived lack of opportunities for collaboration and less exchange of ideas that may facilitate personal and career development. ${ }^{17}$

The association of burnout in older urologists ( $>47$ years old) with employment at an academic institution may be related to the continued requirements of research, teaching, and administration that influence work-life balance. Overall, burnout rates among late-career urologists and other physicians have been consistently low. The protective 
effect of age is attributed to seniority, clinical autonomy, being pleased with life accomplishments, and achieving work-life balance. ${ }^{17,26,34-36}$ There may also be a survivorship bias where physicians who experience significant burnout by mid-career depart from clinical practice.

\section{Burnout in female urologists}

Female gender has not consistently been associated with burnout in studies of urologists. Analysis of the 2016 AUA census did not identify that female gender was associated with burnout compared to males $(p=0.132)$, but their rates of female burnout were lower than that reported in this study $(42.9 \%$ vs. $45.3 \%) .{ }^{17}$ Similarly, a study in Ireland and the United Kingdom did not identify that female gender was associated with burnout $(\mathrm{p}=0.38)$, with rates lower than identified in this study ( $42.1 \%$ vs. $45.3 \%$ ). They did, however, identify that female urologists were more likely to discuss burnout with other colleagues $(p<0.01) .{ }^{26}$ Females general surgeons have been found to have higher job satisfaction than their male colleagues on multivariate analysis (odds ratio [OR] 4.6) ${ }^{35}$ In contrast, Dyrbye et al found that female physicians were less likely to be satisfied with work-life balance with higher rates of burnout in late career compared to men. ${ }^{36}$

In this report, female urologists reported higher rates of burnout than their male colleagues. This was driven by higher rates of DP and low sense of PA. Practice factors associated with burnout among female respondents included spending more time with patients and seeing fewer patients per clinic (Table 5). This is consistent with findings from a survey on Canadian female urologists by Hird et al, who revealed that the greatest sources of career dissatisfaction were seeing more time-consuming patients and managing healthcare resource constraints. ${ }^{37} \mathrm{~A}$ confounder in the current study is that all female respondents that met the criteria for burnout practiced pediatric urology as their primary subspecialty, and the practice factors that were associated with female burnout are common in pediatric urology practice.

Financial strain was associated with burnout in female respondents but not among male respondents. This may be due to the gender pay gap that exists, where women are remunerated less than their male colleagues in urology $^{38}$ and other specialties in medicine. ${ }^{39,40}$ In Canada, urology ranks the most disparate in gross payments to male vs. female physicians (ratio of 1.6). ${ }^{39}$ These gender-based income disparities remain true even after adjustment for age, years in practice, patient factors, and surgical specialty. ${ }^{41}$ This may be explained by the higher proportion of female specific procedures (i.e., slings) performed by female urologists, ${ }^{42}$ and the poorer compensation for female-specific procedures when compared to male-specific procedures of similar complexity. ${ }^{43}$ Hird et al further exposed the financial challenges experienced by female urologists with respect to maternity leave, unequal compensation, fewer referrals for surgical cases, challenges with respect to salary negotiation, and greater administrative work without associated compensation. ${ }^{37}$

Given that only nine female urologists responded to the 2018 CUA census (which was statistically weighted to 53 female urologists), further assessment of burnout among female urologists in Canada is necessary. Hird et al evaluated career satisfaction, personal and professional challenges, and practice barriers among female urologists in Canada, with 60 women completing the survey $(75 \%$ response rate). ${ }^{37}$ They identified that $40 \%$ of women had difficulty finding mentorship in training, $65 \%$ experienced gender discrimination, and that women in community practice were more likely to experience discrimination. Of concern, $30.2 \%$ reported a pregnancy-related complication triggered by their work.

Hird et al recommended that supporting wellness among female urologists requires focused efforts in supporting women on maternity leave, improving mentorship, and prioritizing urology leadership initiatives. ${ }^{37}$ Leaders and organizations, such as the CUA, can help address disparities in support, opportunities, and discrimination. ${ }^{44} \mathrm{~A}$ shift in the culture of practice to become more supportive of women balancing professional and personal demands is necessary. Initiatives that improve female mentorship, child care, and family leave represent areas of opportunity that can be targeted by local and national organizations. ${ }^{44}$

\section{Comparison of CUA and AUA census findings}

Canadian urologists reported lower rates of burnout, EE, and DP compared to their American counterparts (Table 2). Having a more demanding clinical practice and female gender were associated with higher rates of burnout among CUA census respondents when compared to AUA census respondents. Canadian urologists also reported that subspecialty practice and working more efficiently (seeing more patients per week but working fewer hours per week) resulted in a lower proportion of burnout. This is consistent with the protective factors of reduced time spent at work and achieving work-life integration. Differences between these groups may reflect differences between the CUA and AUA census in terms of geography, time, and stratification variables, as well as the different practice and remuneration styles that exist between the two countries. 


\section{Next steps}

The most recent iteration of the Shanafelt et al survey study published in 2019 identified that urology ranked sixth among specialties reporting burnout, but respondents were most dissatisfied with work-life integration. ${ }^{3}$ Initiatives to prevent and manage burnout among Canadian urologists are therefore necessary. A review by Franc-Guimond et al described ways the CUA can address burnout among Canadian urologists, including the promotion of physician healthcare programs, establishing wellness committees, distributing regular wellness surveys, and conducting educational seminars and workshops to trainees and practicing physicians on wellness and burnout. ${ }^{1}$ Some of these initiatives are already in place, including a recent Twitter journal club on burnout, ${ }^{45}$ editorials from leaders in urology, ${ }^{46}$ and educational forums at the 2019 CUA annual meeting. ${ }^{47}$ Additional resources include those provided by the American Medical Association (STEPS Forward) ${ }^{48}$ Canadian Medical Association, ${ }^{49}$ and American College of Surgeons. ${ }^{50}$

This study also identifies groups within Canadian urology that may benefit from directed interventions to reduce burnout, including early-to-mid-career urologists, urologists with demanding clinical practices, female urologists, and urologists experiencing financial strain. We also report that urologists experiencing burnout may have inadequate or inaccessible support resources within their organizations. Specific attention should be made towards improving mentorship resources, as well as accessibility and normalization of childcare and family leave for female urologists. Burnout among Canadian urology trainees continues to require further investigation.

\section{Limitations}

This study is limited by a low number of respondents. In particular, there were few female respondents, which may introduce a selection bias skewed towards the experiences of female pediatric urologists. Despite the low number of respondents, our response rate is similar to that of the 2016 AUA census ${ }^{17}$ and our results are comparable to findings of larger studies of burnout in urology. ${ }^{17,26}$ Furthermore, our findings are statistically weighted by age and region of Canadian urologists to reduce the risk of selection bias.

\section{Conclusions}

Urologists continue to experience burnout at rates that are concerning, though lower than previously identified. The present study is the first to evaluate burnout among Canadian urologists, which is less prevalent than among our colleagues in the United States, ${ }^{17}$ Germany, ${ }^{34}$ Ireland, and the United Kingdom, ${ }^{26}$ though the factors that contribute to burnout are similar between countries. We identify that burnout among Canadian urologists is driven primarily by high work volume (particularly in early-to-mid career), poor work-life integration, financial strain, and female gender.

Burnout can have devastating effects on physician health, delivery of care, and career longevity. There is no panacea for the treatment of burnout, but this report has identified that urologist burnout may be associated with certain demographic and work factors. To best address burnout within our specialty, we must further identify and investigate groups that are at highest risk and tailor interventions to help improve their personal and professional wellbeing at the individual institution level, as well as at the organizational level, including the CUA. We must also direct our efforts into preventing burnout in our workforce and among urology trainees to ensure positive working environments for our future colleagues.

\section{References}

1. Franc-Guimond J, McNeil B, Schlossberg SM, et al. Urologist burnout: Frequency, causes, and potential solutions to an unspoken entity. Can Urol Assoc J 2018;12:137-42. https://doi.org/10.5489/ cuaj. 4668

2. Maslach C, Jackson S, Leiter MP, et al. Maslach Burnout Inventory. Palo Alto, CA: Consulting psychologists press; 1986.

3. Shanafelt TD, West CP, Sinsky C, et al. Changes in burnout and satisfaction with work-life integration in physicians and the general US working population between 2011 and 2017. Mayo Clin Proc 2019;94:1681-94. https://doi.org/10.1016/.mayocp.2018.10.023

4. Leiter MP, Frank E, Matheson TJ. Demands, values, and burnout: Relevance for physicians. Can Fam Physician 2009;55:1224.

5. West CP, Huschka MM, Novotny PJ, et al. Association of perceived medical errors with resident distress and empathy: A prospective longitudinal study. J Am Med Assoc 2006;296:1071-8. https://doi.org/10.1001/jama.296.9.1071

6. Wallace JE, Lemaire JB, Ghali WA. Physician wellness: A missing quality indicator. Lancet 2009;374:1714-21. https://doi.org/10.1016/S0140-6736(09)61424-0

7. West $C P$, Tan AD, Habermann TM, et al. Association of resident fatigue and distress with perceived medical errors. JAMA 2009;302:1294-1300. https://doi.org/10.1001/jama.2009.1389

8. Shanafelt TD, Balch CM, Bechamps $G$, et al. Burnout and medical errors among American surgeons. Ann Surg 2010;251:995-1000. https://doi.org/10.1097/SLA.0b013e3181bfdab3

9. Dyrbye LN, Shanafelt TD. Physician burnout: A potential threat to successful healthcare reform. JAMA 2011;305:2009-10. https://doi.org/10.1001/jama.2011.652

10. Shanafelt TD, Mungo M, Schmitgen J, et al. Longitudinal study evaluating the association between physician burnout and changes in professional work effort. Mayo Clin Proc 2016;91:422-31. https://doi.org/10.1016/i.mayocp.2016.02.001

11. Dewa CS, Jacobs P, Thanh NX, et al. An estimate of the cost of burnout on early retirement and reduction in clinical hours of practicing physicians in Canada. BMC Health Serv Res 2014;254. https://doi.org/10.1186/1472-6963-14-254

12. Shanafelt TD, Balch CM, Dyrbye L, et al. Special report: Suicidal ideation among American surgeons. Arch Surg 2011;146:54-62. https://doi.org/10.1001/archsurg.2010.292

13. West $C P$, Tan AD, Shanafelt TD. Association of resident fatigue and distress with occupational blood and body fluid exposures and motor vehicle incidents. Mayo Clin Proc 2012;87:1138-44. https://doi.org/10.1016/i.mayocp.2012.07.021

14. Shanafelt TD, Boone $S$, Tan $L$, et al. Burnout and satisfaction with work-life balance among US physicians relative to the general US population. Arch Intern Med 2012;172:1377-85. https://doi.org/10.1001/archinternmed.2012.3199 
15. Shanafelt TD, Hasan 0, Dyrbye LN, et al. Changes in burnout and satisfaction with work-life balance in physicians and the general US working population between 2011 and 2014. Mayo Clin Proc 2015;90:1600-13. hitps://doi.org/10.1016/i.mayocp.2015.08.023

16. Penson DF. Re: Changes in burnout and satisfaction with work-life balance in physicians and the general US working population between 2011 and 2014. J Urol 2016;195:1568. https://doi.org/10.1016/ji.uro.2016.02.051

17. North AC, McKenna PH, Fang R, et al. Burnout in urology: Findings from the 2016 AUA annual census. Urol Pract 2018;5:489-94. https://doi.org/10.1016/j.urpr.2017.11.004

18. Rosen IM, Gimotty PA, Shea JA, et al. Evolution of sleep quantity, sleep deprivation, mood disturbances, empathy, and burnout among interns. Acad Med 2006;81:82-5. https://doi.org/10.1097/00001888-200601000-00020

19. Shanafelt TD, Bradley KA, Wipf JE, et al. Burnout and self-reported patient care in an internal medicine residency program. Ann Intern Med 2002;136:358-67. https://doi.org/10.7326/0003-4819-1365-200203050-00008

20. Thomas NK. Resident burnout. J Am Med Assoc 2004;292:2880-9. https://doi.org/10.1001/ jama.292.23.2880

21. Panagopoulou E, Montgomery A, Benos A. Burnout in internal medicine physicians: Differences between residents and specialists. Eur I Intern Med 2006; 17:195-200. https://doi.org/10.1016/i. eiim.2005.11.013

22. Kristensen TS, Borritz M, Villadsen E, et al. The Copenhagen Burnout Inventory: A new tool for the assessment of burnout. Work Stress 2005;19:192-207. https://doi.org/10.1080/02678370500297720

23. Oquendo MA, Bernstein CA, Mayer LES. A key differential diagnosis for physicians - major depression or burnout? JAMA Psychiatry 2019;76:1111. htrps://doi.org/10.1001/jamapsychiatry.2019.1332

24. Graham J, Potts HWW, Ramirez AJ, et al. Stress and burnout in doctors [4] (multiple letters). Lancet 2002;360:1975-6. https://doi.org/10.1016/S0140-6736(02)11871-X

25. Shanafelt $T D$, Balch CM, Bechamps $\mathrm{GJ}$, et al. Burnout and career satisfaction among American surgeons. Ann Surg 2009;250:463-70. https://doi.org/10.1097/SLA.0b013e3181ac4dfd

26. O'Kelly F, Manecksha RP, Quinlan DM, et al. Rates of self-reported "burnout" and causative factors amongst urologists in Ireland and the UK: A comparative cross-sectional study. BJU Int 2016;117:36372. https://doi.org/10.1111/bju.13218

27. Oskrochi $Y$, Maruthappu $M$, Henriksson $M$, et al. Beyond the body: A systematic review of the nonphysical effects of a surgical career. Surgery 2016;159:650-64. https://doi.org/10.1016/i. surg.2015.08.017

28. Campbell DA, Sonnad SS, Eckhauser FE, et al. Burnout among American surgeons. Surgery 2001;130:696-705. https://doi.org/10.1067/msy.2001.116676

29. Collier R. Electronic health records contributing to physician burnout. CMAJ 2017;189:E1405-6. https://doi.org/10.1503/cmaj.109-5522

30. Kroth PJ, Morioka-Douglas N, Veres S, et al. Association of electronic Health Record Design and Use Factors With Clinician Stress and Burnout. JAMA Netw Open 2019;2(8):e199609. https://doi.org/10.1001/jamanetworkopen.2019.9609

31. Melnick ER, Dyrbye LN, Sinsky CA, et al. The association between perceived electronic health record usability and professional burnout among US physicians. Mayo Clin Proc 2020;95:476-87. https://doi.org/10.1016/i.mayocp.2019.09.024

32. Pruthi NR, Deal A, Langston J, et al. Factors related to job satisfaction in urology. Urol Pract 2016;3:16974. https://doi.org/10.1016/i.urpr.2015.06.001

33. Cheng JW, Wagner H, Hernandez BC, et al. Stressors and coping mechanisms related to burnout within urology. Urology 2020;139:27-36. https://doi.org/10.1016/i.urology.2019.11.072
34. Böhle A, Baumgärtel M, Götz ML, et al. Burn-out of urologists in the county of Schleswig-Holstein, Germany: A comparison of hospital and private practice urologists. J Urol 2001;165:1158-61. https://doi.org/10.1016/S0022-5347(05)66454-3

35. Raptis DA, Schlegel A, Tschuor C, et al. Job satisfaction among young board-certified surgeons at academic centers in Europe and North America. Ann Surg 2012;256:796-803. https://doi.org/10.1097/ SLA.0b013e31827386eb

36. Dyrbye LN, Varkey P, Boone SL, et al. Physician satisfaction and burnout at different career stages. Mayo Clin Proc 2013;88:1358-67. https://doi.org/10.1016/i.mayocp.2013.07.016

37. Hird AE, St-Laurent MP, Nadeau $G$, et al. Exploring the patterns of practice and satisfaction among female urologists in Canada. Can Urol Assoc J 2020; 14:245-51. https://doi.org/10.5489/cuaj.6184

38. Spencer ES, Deal AM, Pruthi NR, et al. Gender differences in compensation, job satisfaction, and other practice patterns in urology. J Urol 2016;195:450-5. https://doi.org/10.1016/i.juro.2015.08.100

39. Cohen M, Kiran T. Closing the gender pay gap in Canadian medicine. CMAJ 2020;192:E1011-7. https://doi.org/10.1503/cmai.200375

40. Ly DP, Seabury SA, Jena AB. Differences in incomes of physicians in the United States by race and sex: Observational study. BMJ 2016;353. https://doi.org/10.1136/bmj.i2923

41. Dossa F, Simpson AN, Sutradhar R, et al. Sex-based disparities in the hourly earnings of surgeons in the fee-for-service system in Ontario, Canada. JAMA Surg 2019;154:1134-42. https://doi.org/10.1001/ jamasurg.2019.3769

42. Oberlin DT, Matulewicz RS, Bachrach L, et al. National practice patterns of treatment of erectile dysfunction with penile prosthesis implantation. J Urol 2015;193:2040-4. https://doi.org/10.1016/i. juro.2014.11.095

43. Benoit MF, Ma JF, Upperman BA. Comparison of 2015 Medicare relative value units for genderspecific procedures: Gynecologic and gynecologic-oncologic vs. urologic CPT coding. Has time healed gender-worth? Gynecol Oncol 2017;144:336-42. https://doi.org/10.1016/i.ygyno.2016.12.006

44. Templeton K, Bernstein CA, Sukhera J, et al. Gender-based differences in burnout: Issues faced by women physicians. NAM Perspect, May 30, 2019. https://doi.org/10.31478/201905a

45. November 2019 \#CUAJC/Twitter. Available at: https://twitter.com/i/ events/1199510494278832129. Accessed Dec. 11, 2020.

46. Koyle MA, Siemens DR. I didn't think it could (would) happen to me. Can Urol Assoc J 2019;13:79-80. https://doi.org/10.5489/cuai.5950

47. CUA 74th Annual Meeting - Mobis. Available at: https://2019.cua.events/mobis/timeslot/10. Accessed Dec. 11, 2020.

48. AMA Ed Hub. Real-world solutions to enhance clinical practice. Available at: https://edhub.ama-assn. org/steps-forward. Accessed Dece. 27, 2020.

49. Burnout Resources - CMA. Available at: https://www.cma.ca/physician-wellness-hub/topics/burnout. Accessed Dec. 27, 2020

50. Surgeon well-being. Available at: https://www.facs.org/member-services/surgeon-wellbeing. Accessed Dec. 27, 2020.

Correspondence: Dr. Alp Sener, Department of Surgery, Division of Urology, Schulich School of

Medicine \& Dentistry, Western University, London, ON, Canada; Alp.sener@hths.on.ca 